\title{
Irritable bowel syndrome - from etiopathogenesis to therapy
}

\author{
Biljana Radovanovic-Dinic ${ }^{\mathrm{a}, \mathrm{b}}$, Snezana Tesic-Rajkovic ${ }^{\mathrm{a}}$, Sasa Grgov', Gordana Petrovic ${ }^{\mathrm{a}}$, Valentina Zivkovic ${ }^{\mathrm{b}, \mathrm{d}}$
}

\begin{abstract}
Irritable bowel syndrome (IBS) is a chronic and relapsing functional gastrointestinal disorder that affects $9-23 \%$ of the population across the world. Patients with IBS are often referred to gastroenterology, undergo various investigations, take various medicines, take time off work and have a poor quality of life. The pathophysiology of IBS is not yet completely understood and seems to be multifactorial. Many pathogenetic factors, in various combinations, and not all necessarily present in each patient, can play an important role. Discomfort or abdominal pain relieived by defacation, asociated with a change in stool form, is a typical clinical manifestation of IBS. Many factors, such as emotional stress and eating, may exacerbate the symptoms. A timely diagnosis of IBS is important so that treatment which will provide adequate symptomatic relief (diarrhoea, constipation, pain and boaring) can be introduced. The diagnosis of IBS is not confirmed by a specific test or structural abnormality. It is made using criteria based on clinical symptoms such as Rome criteria, unless the symptoms are thought to be atypical. Today the Rome Criteria IV is the current gold-standard for the diagnoses of IBS. Treatment of patients with IBS requires a multidisciplinary approach. Some patients respond well to non-pharmacological treatment, while others also require pharmacological treatment. This review will provide a summary of pathophysiology, diagnostic criteria and therapies for IBS.
\end{abstract}

Key words: irritable bowel syndrome, pathogenesis, diagnosis, Rome criteria, therapy

Received: August 8, 2017; Accepted with revision: December 12, 2017; Available online: January 18, 2018 https://doi.org/10.5507/bp.2017.057

${ }^{a}$ Clinic for Gastroenterology and Hepatology, Clinical Centre Nis, Serbia

${ }^{b}$ Faculty of Medicine, University of Nis, Serbia

'General Hospital, Leskovac, Serbia

dInstitute for Treatment and Rehabilitation, Niska Banja, Serbia

Corresponding author:Biljana Radovanovic-Dinic, e-mail:bikius@yahoo.com

\section{INTRODUCTION}

Irritable bowel syndrome (IBS) is a chronic, relapsing, remitting and the most prevalent functional disorder of the gastrointestinal tract. This disease is characterized by abdominal pain, bloating, and changes in bowel habits that lack a known structural or anatomic explanation ${ }^{1-3}$. Over the years, the unexplained gastrointestinal symptoms of IBS have been described in various terms, including mucous colitis, spastic colitis, nervous colon, and irritable colon ${ }^{4}$. The symptoms of IBS appear and dissapear over time, and are often associated with other functional gastrointestinal dieases and non-gastrointestinal somatic pain disorders ${ }^{5}$. Patients with IBS are often referred to gastroenterology, undergo various investigations, take various medicines, take time off work and have a poor quality of life. However, there is a large number of patients that do not report to the doctor's office or seek medical attention ${ }^{6,7}$. The first case of IBS was described by Osler in 1982 as 'mucosal colitis'. Patients complained of abdominal pain and in the main were hysterical, hypochondriacs or depressed. The term 'irritable colon' first appeared in the medical literature when it was ued by Jordan and Kiefer to describe a colonic musculoneural disorder present in $30 \%$ of gastroenterology outpatients. Despite the large number of studies that attempt to explain IBS, the disease continues to present as a challenge in the 21 st century 8 .

\section{EPIDEMIOLOGY}

IBS is a chronic and debilitating functional gastrointestinal disorder that affects $9-23 \%$ of the population across the world ${ }^{7}$. Women are two to four times more likely to develop IBS than men'. Age-related onset of IBS symptoms occurred predominantly in patients younger than 45 years but prevalence rose again in the elderly ${ }^{10}$. Many cases develop in early childhood ${ }^{11}$. The development of symptoms in people older than 40 years does not exclude IBS but should prompt a closer search for an underlying organic etiology ${ }^{7}$. The prevalence varies according to country and criteria used to define IBS. The effects of socioeconomic status have not been well described ${ }^{9,12}$. The role of different cultural influences and varying health care-seeking behaviors is unclear ${ }^{11,12}$.

\section{ETHIOPATHOGENESIS}

Despite its high prevalence, the pathophysiology of IBS is not yet completely understood and seems to be multifactorial $1^{46,13,14}$. Many pathogenetic factors (Table 1), in various combinations, and not all necessarily present in each patient, can play an important role ${ }^{15}$. It is unclear which among these factors is the trigger or how these conditions converge to initiate IBS. 
Table 1. Factors potentially involved in the pathogenesis of irritable bowel syndrome ${ }^{15}$.

1. Genetic predisposition

2. Altered intestinal motility

3. Intestinal hypersensitivity

4. Psychological distress and disorders; sexual abuse

5. Enteric infection/inflammation

6. Altered intestinal immunity

7. Altered gut microbiota

8. Food intolerance

\section{Genetic predisposition}

The influence of genetic predisposition in the development of IBS has been well researched. A positive family history for IBS is present in $33 \%$ of patients ${ }^{15}$. Having a parent with IBS is a greater predictive factor for IBS than having a twin with IBS, which indicates that environmental factors may play a greater role than genetic ones ${ }^{16}$.

A number of studies have investigated the possible role of gene polymorphisms coding for anti-inflammatory and pro-inflammatory interleukins, alpha 2 adrenergic receptors, serotonin (SERT) and cholecystokinin (CCK) receptors ${ }^{17}$. There is a significant correlation between SERT polymorphisms and IBS symptom severity, although their possible direct causal role remains to be proven. In addition, the present findings do not support an association of SERT with IBS or its clinical presentation in terms of bowel habit predominance ${ }^{18}$. Traditionally, IBS has been conceptualized as a condition of altered intestinal motility (leading to diarrhea or constipation), intestinal hypersensitivity (leading to abdominal discomfort or pain), and psychopathology $y^{7,19}$.

\section{Altered intestinal motility}

In patients with IBS, environmental stress or strong emotion via the brain-gut axis can lead to dysmotility throughout the small and large intestine. Patients with IBS have an even greater motility response to stressors when compared with normal subjects ${ }^{20,21}$. Small bowel dysmotility manifests as accelerated meal transit in patients prone to diarrhoea and in delayed meal transit in patients prone to constipation. In addition, patients exhibit shorter intervals between migratory motor complexes (predominantly interdigestive small bowel motor patterns). Colonic dysmotility in IBS manifests as variations in slow-wave frequency and a blunted, late-peaking, postprandial response of spike potentials. Patients who are prone to diarrhea demonstrate these alterations to a greater degree than patients who are prone to constipation ${ }^{22}$.

Serotonin, acting particularly through receptors, plays a significant role in the control of gastrointestinal motility. It has been observed that plasma serotonin concentrations are reduced in IBS patients with constipation, but raised in those with diarrhoea. There has been considerable interest in these receptors as possible therapeutic targets for IBS, with agonists or antagonists at the serotonin receptor ${ }^{23-25}$.

\section{Intestinal hypersensitivity}

Intestinal hypersensitivity is a multifactorial process that may occur within the peripheral or central nervous systems and plays a principal role in the etiology of IBS (ref. $\left.{ }^{25}\right)$.

This selective hypersensitization occurs as a result of stimulation of various receptors of visceral afferent nerve fibres in the gut wall, triggered by bowel distention or bloating, and is a possible explanation for IBS symptoms. The increased sensitivity of the colon could be influenced by a psychological tendency to report pain and urgency, rather than increased neurosensory sensitivity ${ }^{26,27}$.

\section{Psychopathology}

There is a clear increased prevalence of current psychological distress among patients who seek medical care for IBS. Symptoms of anxiety, depression, paranoia and global psychological symptoms are commonly encountered in these patients. A study has suggested that patients with IBS may have suicidal ideation and/or suicide attempts strictly as a result of their bowel symptoms. Several studies have demonstrated higher levels of physical and sexual abuse among IBS patients compared with patients in other medical clinics ${ }^{7}$.

Patients with IBS who do not present for care generally have a normal psychological profile, although some surveys show increased psychosocial distress of intermediate severity ${ }^{28}$. Limbic system abnormalities, as demonstrated by positron emission tomography, have been described in patients with IBS (ref. ${ }^{29}$ ). Koloski et al conducted a 12-year longitudinal, prospective, populationbased study on the brain-gut axis and concluded that the central nervous system and gut interact bidirectionally in functional gastrointestinal disorders ${ }^{30}$. Psychological disorders can affect the brain-gut axis, promoting the release of corticotropin-releasing hormone, which is able to influence mood, digestive motility, visceral sensitivity and inflammatory pathways via neuroendocrine and autonomic outflows ${ }^{31}$. Stress in IBS patients increases the levels of pro-inflammatory interleukins, activating both the hypothalamic-autonomic nervous system and the hypothalamic-pituitary-adrenal (HPA) axes and consequently increases the serological adreno-cortico-tropic-hormone and cortisol levels ${ }^{32}$.

\section{Enteric infection/inflammation}

Enteric inflammation has been noted in some patients with IBS after prolonged infectious enteritis (postinfectious IBS) ( ref. $^{15}$ ). In patients with Giardia lamblia infection the prevalence of IBS was $46.1 \%$ as long as 3 years after exposure, compared with $14 \%$ in controls ${ }^{33}$. The mechanisms that cause postinfectious IBS are unknown but could include residual inflammation or persistent changes in mucosal immunocytes, enterochromaffin and mast cells, enteric nerves, and the gastrointestinal microbiota ${ }^{7}$. Vomiting during initial enteric infection may decrease the risk of postinfectious IBS, possibly by decreasing the pathogen load in the distal gastrointestinal $\operatorname{tract}^{34}$. 


\section{Altered gut microbiota}

Differences in the bacterial composition of the gut and also reduced fecal microbial diversity in IBS patients, relative to healthy individuals, have implied a causative role in the onset and maintenance of IBS (ref. ${ }^{35}$ ). The microbiota is altered in IBS and such alterations may contribute to the pathogenesis of the disorder through, for example, increased permeability, an altered immune profile, effects on gut-brain axis and modulation of gut neuromuscular function ${ }^{36}$. Lactobacilli and bifidobacteria were found to be decreased in IBS patients, and their activities were found to be heavily compromised ${ }^{15}$. Furthermore, there is evidence that probiotics can affect intestinal fermentation and stabilise microbiotia, normalising the relationship between pro- and anti-inflammatory cytokines. This results has a beneficial effect on intestinal inflammation, permeability and visceral sensitivity ${ }^{37}$.

\section{Food intolerance}

Patients with IBS tend to report that their symptoms are often exacerbated by certain foods. The classical IgEmediated food allergy does not seem to play an important role in IBS (ref. ${ }^{38}$ ). In recent years, it has been observed that the ingestion of gluten causes abdominal discomfort and IBS-like symptoms in subjects without a diagnosis of celiac disease (the so-called gluten sensitivity). Most likely, the gluten, like other well-known factors, alters the intestinal permeability, activating the enteric and autonomous nervous systems and producing the typical symptoms of IBS ( ref. $^{39,40}$ ).

\section{CLINICAL MANIFESTATIONS}

Discomfort or abdominal pain relieived by defacation, asociated with a change in stool form, is a typical clinical manifestation of IBS ( ref. $^{4}$ ). Many factors, such as emotional stress and eating, may exacerbate the pain. Patients with IBS complain of altered bowel habits, ranging from diarrhoea, constipation, or alternating diarrhoea and constipation; up to a third of patients will move from one group to another. Patients with IBS and constipation may experience a sensation of incomplete evacuation and periods of constipation can last from days to months, alternating with diarrhoea or normal bowel function ${ }^{41}$. Bloating or a feeling of abdominal distension are very frequent complaints in IBS and may be included in the diagnostic criteria for IBS in the future. Bloating is an important symptom of IBS and must be part both of the symptom complex and of the outcome measures of drug trials $^{42}$. Most adults with the condition, experience episodes of symptom exacerbation, followed by periods of remission.

IBS is often also associated with other digestive symptoms as dysphagia, dyspepsia, nausea and non-cardiac chest pain. Comorbidity with other functional gastrointestinal disorders (FGIDs) is high and can be caused by shared visceral hypersensitivity pathophysiological mechanisms ${ }^{4,5}$. Fibromyalgia, chronic fatigue syndrome, temporomandibular joint disorder and chronic pelvic pain are nongastrointestinal disorders with a well-documented association with IBS(ref. ${ }^{4}$ ). Also frequently associated are psychiatric disorders including major depression, anxiety and somatoform disorders ${ }^{43}$. These comorbidities are linked with a greater need to seek medical attention, a worse prognosis, and a higher rate of anxiety and depression, all of which contribute to a reduced quality of life ${ }^{44}$. It is important to recognize these symptoms as part of the IBS symptomatology and avoid unnecessary additional specialist examinations.

\section{DIAGNOSIS}

A timely diagnosis of IBS is important so that treatment which will provide adequate symptomatic relief (from diarrhoea, constipation, pain and flatulance) can be introduced. Research indicates that many primary care providers are unaware of the diagnostic criteria for IBS and that these patients are often referred to specialist gastroenterologists for further diagnostic testing ${ }^{45}$. Yet the majority of patients can be managed effectively by physicians in the primary care setting at a lower cost ${ }^{46}$. Though, when making a diagnosis, consideration should be given to the fact that the symptoms of IBS are similar to those of organic disorders and can co-exist with organic diseases.

The first attempt at establishing a diagnostic criteria that would define IBS dates back to 1970 by Manning and associates ${ }^{47}$. Following this, more attention was paid to this functional digestive problem, such that in Rome, a Rome Foundation was formed which played a pivotal role in creating a diagnostic critera and operationalizing the dissemination of new knowledge in the field of all functional gastrointestinal disorders. The Rome I criteria was published in 1990, Rome II criteria in 1999 and Rome III criteria in 2006. Rome IV criteria is a compendium of the knowledge accumulated since Rome III was published 10 years ago ${ }^{48-50}$. The development of the Rome IV criteria (Table 2) took place over a six-year period involving the input from more than 100 experts worldwide ${ }^{51}$. Although the Rome diagnostic criteria for IBS are widely used in clinical trials, there is recognition that they are not often used in clinical practice ${ }^{52}$.

It is important to ask the patient to clarify the timing, severity, and location of their pain or discomfort, and whether this is generalised abdominal pain. Four bowel patterns may be seen with IBS, and these remain in the Rome IV classification ${ }^{53}$.

- IBS-D (diarrhoea predominant)

- IBS-C (constipation predominant)

Table 2. Rome IV Criteria for Diagnosing IBS (ref. ${ }^{51}$ ).

Recurrent abdominal pain at least 1 day/week in the last 3 months, with at least two of the following criteria:

- Related to defecation

- Associated with a change in frequency of stool

- Associated with a change in form (appearance) of stool The criteria should be met for the last 3 months and the symptoms begin at least 6 months before diagnosis. 
- IBS-M (mixed diarrhoea and constipation)

- IBS-U (unclassified; the symptoms cannot be categorized into one of the above three subtypes)

Patients may experience a change from one IBS subtype to another with time. In patients who meet the diagnostic criteria for IBS, other digestive diseases should be excluded, and the following investigations be undertaken: blood count, biochemical and inflammatory markers and immunological tests for celiac disease. The following investigations in such patients are unecessary: ultrasound scanning of the abdomen, rectosigmoidoscopy or colonoscopy or irrography, thyroid and parathyroid analysis, stool analysis (parasites, bacteria, in particular Clostridium difficile toxin, and possibly Giardia antigen, occult bleeding test Lactose intolerance). The decision to undertake further investigations is dependent on the presence of other risk factors or alarming symptoms (Table 3) (ref. ${ }^{11}$ ). For individuals aged less than 50 years, that meet the criteria for IBS, there should be no further bowel examination if the following features aren't present: weight loss, hypochromic anemia and/or family history of certain GI illnesses. In patients with IBS-D, a differential diagnostic that includes the following should be considered: microscopic colitis, ulcerative colitis, Crohn's disease, celiac disease, Giardiasis, lactose malabsorption, tropical sprue, bacterial small bowel contamination, malabsorption of bile salts and colorectal cancer.

In patients with IBS-D, a differential diagnostic that includes the following should be considered: microscopic colitis, celiac disease, Giardiasis, lactose malabsorption, tropical sprue, bacterial small bowel contamination, malabsorption of bile salts and colorectal cancer.

\section{TREATMENT}

Before commensing with treatment, the patient should be educated and made aware of the nature of IBS. Amongst other things, patients should be informed about the normal frequency of intestinal emptying, which ranges from three times per day to three times a week. Treatment of patients with IBS requires a multidisciplinary approach. Treatment is on an individual basis and dependent on the dominant symptoms. Not all patients respond to the same treatment. Particular attention should be paid to aggravating factors in IBS such as nutrition, stress, and psychological factors. Some patients respond well to nonpharmacological treatment, while others require pharmacological treatment.

\section{Non-pharmacological treatment}

Increased physical activity improves symptoms in IBS-C. Physically active patients with IBS-C will face less symptom deterioration compared with physically inactive patients. Physical activity should be used as a primary treatment modality in IBS-C. However, excessive exercise is not recommended ${ }^{54}$. An increase in physical activity in IBS-C patients contributes to accelerating transit through
Table 3. Alarm symptoms that suggest organic intestinal disease $^{11}$.

- A change in bowel habit to looser and/or more frequent stools persisting for more than six weeks in an individual aged

- Family history of bowel or ovarian cancer

- Rectal bleeding

- Rectal masses

- Abdominal masses

- Anaemia

- Unintentional and unexplained weight loss

- Raised inflammatory markers

Table 4. Clinical Guidelines for modifying nutritional intake in IBS patients ${ }^{11}$.

- Eat regular meals and allow enough time for them

- Drink at least 8 glasses of fluids, particularly water or other non-caffienated drinks during the day. Restrict coffee or tea to 3 cups per day.

- When it hasn't led to an improvement, limit the intake of high-fiber foods (such as wholemeal flour and breads, cereals high in bran, and whole grains such as brown rice).

- Reduce the intake of "resistant starch"

- Limit the intake of fresh fruit to 3 portions per day (a portion is approximately $80 \mathrm{~g}$ )

- Reduce the intake of alcohol and fizzy drinks.

- In IBS-D avoid the artificial sweetener Sorbitol

- In cases of bloating or flatulance oats may be helpful.

the colon and reducing bloating ${ }^{55}$. The correlation between nutrition and its effect depends on the type of IBS; the same nutritional advice can't be applied to all IBS patients. It is recommended that patients keep a diet diary where they can record which foods lead to symptoms. Patients with IBS often state that certain food types aggravate their symptoms, for example caffeine, dairy products and cereals, and artificial sweeteners ${ }^{56}$.

In some patients, the intake of gluten exacerbates symptoms, without any evidence of celiac disease, which is associated with hypersensitivity to gluten, and it is advised to discontinue it. Volta et al evaluated current evidence and suggested that patients with gluten/wheat sensitivity may be a subset of those with IBS (ref. ${ }^{57}$ ). Likewise, in some patients with IBS, fats and lactose can be aggravating factors due to the existence of intolerance or sensitivity to fat and lactose ${ }^{58}$. In the past few years, a diet low in fermentable oligosaccharides, disaccharides, monosaccharides, and polyols (FODMAPs) has been embraced by patients with IBS, particularly those with IBS-D or patients who have symptoms of bloating ${ }^{59}$. National Institute for Health and Care Excellence Gave recommendations for modifying nutritional intake in IBS (Table 4) (ref. ${ }^{11}$ ).

In cases where a strict diet has not resulted in an desirable outcome, pharmacological therapy is recommended. 


\section{Pharmacological treatment}

Choice of pharmacological therapy should be based on the nature and severity of the patient's predominant symptoms.

\section{Laxatives}

Various laxative preparations are available for the management of IBS-C and IBS-M (mixed diarrhoea and constipation) when diet correction and physical activity have not lead to improvement. Laxatives can help regulate intestinal discharge but do not relieve abdominal pain ${ }^{60}$. The patient should be warned that during treatment they may have an increased bloating and that the effect of the medication will better if its intake is followed by fluids. Laxatives include bulk-forming, stimulant and osmotic laxatives ${ }^{11}$.

A bulk-forming laxative absorbs liquid in the intestines. This creates a bulky, more liquid stool that's softer and easier to pass. Bulk-forming laxatives are different from other laxatives. They're most similar to stool softeners in that they help the bowels retain water. They're often the first line of defense before stimulant or other types of laxatives are used. There is also less risk of cramping or explosive diarrhoea that occurs with stimulant laxatives ${ }^{61}$.

A stimulant laxative is recommended in patients that have neat, soft stools which are hard to pass. They are recommended for short-term occasional use since they can cause addiction. Stimulant laxatives are associated with tachyphylaxis and dependency ${ }^{56}$. In practice Bisacodyl or Senna are used mainly ${ }^{11}$. Lubiprostone is an agonist of the type 2 chloride channel. Lubiprostone increases the secretion of the chloride-rich fluid and lumbrication of the intestinal lumen. These secretions soften the stool, increase motility, and promote spontaneous bowel movements. Lubiprostone is a safe and efficacious drug for the treatment of IBC-C. Despite the efficacy, the side effects (e.g., nausea, abdominal pain) and the high cost may limit the use of lubiprostone ${ }^{62,63}$. Linaclotide is a minimally absorbed peptide guanylate cyclase- $\mathrm{C}$ agonist which increases the secretion of fluid into the intestinal lumen. The secretion of fluids increased transit, likely through stimulation of local receptors sensitive to stretch and distention. On the basis of a meta-analysis, linaclotide improves bowel function and reduces abdominal pain, bloating and overall symptom severity of IBS-C (ref. ${ }^{64,65}$ ).

If stools remain hard, osmotic laxatives, such as macrogols, should be introduced. Lactulose is not recommended for IBS patients because it significantly increases bloating. Polyethylene glycol laxatives may be useful in patients with IBS-C for specific symptom relief or as adjunctive treatment ${ }^{11,47}$.

\section{Antidiarrhoeals}

IBS-D can be debilitating and there are limited therapeutic options for managing the chronic symptoms. Due to accelerated peristalsis, increased frequency and urgency of having bowel movements in patients with IBS-D, antidiaretics are recommended ${ }^{11}$. Antidiarrhoeals prolong the time taken for contents to pass through the colon, increase segmental contractions of the colon, increase anal pressure and reduce rectal perception. It is advised to take them $30 \mathrm{~min}$ before mealtime. In clinical practice, Loperamide hydrochloride is the most commonly used, which reduces the frequency and urgency of emptying, improves stool consistency, reduces borborigma, and greatly improves the condition of patients with IBS-D and IBS-M. However, it does not relieve pain, bloating, or other global irritable bowel syndrome symptoms ${ }^{66}$. Because of its low cost, wide availability, and minimal adverse effects, loperamide can be viewed as a useful adjunct to other IBS-D therapies $^{67,68}$.

Cholestyramine is the medication of choice in patients with IBS-D with proven malabsorption of bile acids ${ }^{69}$.

Eluxadoline is a locally acting, mixed mu opioid receptor $(\mu \mathrm{OR})$ agonist/delta opioid receptor $(\delta \mathrm{OR})$ antagonist with low oral bioavailability, with a proposed indication in adults for the treatment of IBS-D. Eluxadoline is a new therapeutic agent that reduced symptoms of IBS with diarrhea, with sustained efficacy over 6 months in patients who received the $100-\mathrm{mg}$ dose twice daily ${ }^{70}$. However, Eluxadoline may increase the risk of the pancreatitis in patients with heavy alcohol use ${ }^{71,72}$. Asimadoline, a kappa-opioid receptor agonist, acts peripherally, inducing analgesic and antidiarrheal effects. Patients treated with asimadoline have a significant relief of IBS pain, urgency and frequency of intestinal discharge ${ }^{73}$.

\section{Antispasmodics}

Antispasmodics (Anticholinergic agents) are the medication of choice in patients with discomfort or abdominal pain. They work by causing relaxation of smooth muscle in the bowel. In clinical practice, mebeverine hydrochloride, hyoscyamine butylbromide and peppermint oil are commonly used ${ }^{61}$. These medications are best taken 20$30 \mathrm{~min}$ before meals, three times per day. Hyoscyamine works by blocking acetylcholine action at parasympathetic sites in smooth secretory glands, smooth muscle and the CNS, resulting in antispasmodic effects. It also reduces faecal urgency and pain ${ }^{74}$.

\section{Probiotics}

Probiotics consist of a preparation containing a single- or mixed-culture of live microbes that exert beneficial health effects by altering the gastrointestinal flora ${ }^{74}$. Probiotics can be beneficial to patients with IBS by improving bowel movement frequency, bloating, pain and flatulance ${ }^{75,76}$. They have an antibacterial, antiviral, and anti-inflammatory effect on the mucous membrane surface, so they can prevent or modify the flow of postinfective IBS. Probiotics are interesting for treating symptoms, but it is unclear for which patients probiotics are helpful, and in what form, dose, combination, or strain ${ }^{77,78}$. Despite numerous studies analysing different probiotics, results were inconclusive as to which of them is best in the management of patients with IBS-D $\left(\right.$ ref. $\left.^{79}\right)$.

\section{Fecal microbiota transplantation}

Fecal microbiota transplantation (FMT), often referred to as 'fecal transplant', is a therapeutic procedure that involves infusion of suspension of faeces from a 
healthy person into the gastrointestinal tract of patients with different diseases related to an altered composition of intestinal flora. FMT is considered a therapeutic option for refractory IBS. This particularly applies to postinfective IBS where pronounced dysbiosis is present ${ }^{80,81}$. A positive response to FMT is present in both diarrhoea and constipation predominant IBS. Patients with predominant constipation have increased sulfate and methane producing bacteria, whose toxin inhibit bowel motility and correction of dysbiosis after FMT has a good therapeutic response ${ }^{80}$. Since there are theraputic benefits of FMT in the treatment of constipation, there is potential for such an inexpensive and safe treatment modality to undergo further research into its clinical use ${ }^{82-83}$.

\section{Serotonin receptor agonists and antagonists}

Given that serotonin activates internal and external primary afferent neurons to initiate peristalsis and secondary reflexes to transmit sensory information to the central nervous system, serotonin receptor agonists and antagonists have found a purpose in the treatment of IBS.

Alosetron is a selective serotonin antagonist that acts at the 5-hydroxytryptamine (5-HT) type 3 receptor $^{61}$. Alosetron reduces the pain, discomfort, frequency and urgency of defecation. However, this medicine can induce ischemic colitis and obstipation and so it is recommended only for women who have severe IBS with dominant diarrea lasting longer than 6 months which has not responded adequately to conventional therapy ${ }^{84-86}$.

Ramosetron is a potent and selective 5-HT type 3 receptor antagonist. A recent systematic review and meta-analysis concluded that ramosetron is efficacious in patients with IBS-D (ref. ${ }^{87}$ ).

Tegaserod is a 5-HT type 4 receptor partial agonist. The drug was initially approved by the FDA in 2002 for the treatment of IBS-C in women.In clinical trials, it was shown to be superior to placebo in improving global IBS symptoms, but it was withdrawn from the market in 2007 because of an increased risk of cardiovascular events ${ }^{61}$.

Prucalopride is a very highly selective 5-HT type 4 receptor agonist. Prucalopride reduces abdominal discomfort, bloating, straining, and painful bowel movements. Although no studies have yet evaluated the efficacy of prucalopride in IBS-C (ref. ${ }^{88}$ ).

Renzapride is a full agonist for the 5HT type 4 receptor and an antagonist to 5HT type $2 \mathrm{~b}$ and 5HT type 3 receptors. Studies have shown that Renzapride is not superior to placebo in relieving IBS symptoms ${ }^{88}$.

\section{Psychological therapies}

There is less high-quality evidence for routine use of psychological therapies in IBS, but available data suggest these may be of comparable efficacy There is still insufficient evidence of high quality that would support the routine use of psychological therapies in IBS ( ref. ${ }^{89}$ ).

Antidepressants can be used in the treatment of patients with IBS to counteract the inhibitory motor action on the gut. For this purpose, tricyclic antidepressants (Trimipramine, Imipramine, Amitriptilyn) are most commonly used. Patients with dominant diarrhea or pain may benefit from tricyclic antidepressants, especially if they have a clearly defined depression. Trimipramine has proved to be successful in patients who had vomiting, mucous, abdominal pain, depression and insomnia. In patients with dominant diarrhea, Imipramine slows down the transit through the entire intestine. Amitriptilyn and Desipamine have a beneficial effect on abdominal pain and intestinal discharge. Selective serotonin reuptake inhibitors (Paroxetin, Citalopram) accelerate transit time, which opens the possibility for their use in constipation ${ }^{84,90}$. Patients with prominent anxiety are often intolerant of antidepressants and can be treated with benzodiazepine monotherapy ${ }^{91}$.

\section{Anti-inflammatory therapies}

Rifaximin (rifamycin derivative), a nonabsorbable antibiotic, has been evaluated in patients with IBS-D. Rifaximin improves IBS symptoms through a variety of mechanisms directed at the gastrointestinal tract. The FDA approved rifaximin in IBS-D "naive" patients at a dose of $550 \mathrm{mg}$ three times a day for $14 \mathrm{~d}$ as well as in patients experiencing a recurrence of symptoms. This antibiotic is relatively safe, lacks significant drug-drug interactions. This may make rifaximin a possible initial or second-line treatment option for patients with IBS-D (ref. $\left.{ }^{70,86}\right)$.

It is necessary that further studies prove the efficacy of Corticosteroids, Mast cell stabilizers and Mesalazine for IBS therapy ${ }^{86}$.

\section{THE RECOMMENDATION FOR CLINICAL PRAXIS}

When determining IBS therapy, one should first determine which type of IBS is it, or which are the dominant symptoms and signs. Today, there are various groups of drugs for the treatment of IBS. However, despite the positive therapeutic effect, some drugs have their limitations in the view of not being able to be used for a long time, or they have contra-indications or side-effects. However, this should not discourage doctors, especially those of primary health care, when deciding to start with IBS therapy. Treatment should begin gradually using a non-pharmacological treatment in accordance with IBS type. In the case where a non-pharmacological treatment does not lead to improvement, a pharmacological therapy should be added. Begin therapy with one, possibly two medicaments (most commonly added to the IBS-C antispasmodics). Therapy should be started with a medicament that has the most experience in clinical practice. Despite numerous studies that have considered numerous therapeutic options, an ideal IBS therapy algorithm cannot yet be formed.

\section{PROGNOSIS}

In most patients with IBS symptoms persists but they do not worsen, while the rest may experience worsening 
or complete resolution. Factors that may contribute to a poor prognosis include:

- Uncertainty or doubt with regards to the effect of medicinal therapy

- Damage to the bowel as a result of existing symptoms

- Long standing IBS

- Chronic stress exposure

- Comorbidity of psychiatric illnesses

\section{CONCLUSION}

Despite numerous studies, the etiopathogenesis of irritable bowel syndrome is still unclear. However, in the last few decades diagnostic and therapeutic possibilities have prospered. The understanding that IBS is a result of a interaction between social, biological and psychological factors points to the need to consider all of these in order to prevent and treat this syndrome. It is a doctor's task to educate patients about the functional nature of IBS, which will not endanger them, but can have a significant impact on quality of life. Despite numerous therapeutic options, there is still no ideal IBS therapy algorithm.

\section{Search strategy and selection criteria}

We examined articles and studies from various resources (e.g. PubMed, MEDLINE). Only English language papers were reviewed. The search terms used included irritable bowel syndrome, functional gastrointestinal disorder and Rome Criteria. Citation from journals from recet date and with high impact factors were used.

Acknowledgement: The authors would like to thank dr Lara Zebic BDS from Birmingham in England, for her helpful advice.

Author contributions: Both authors contributed in writing the manuscript. All authors read and approved the final manuscript.

Conflict of interest statement: The authors certify that they have no affiliations with or involvement in any organization or entity with any financial interest.

\section{REFERENCES}

1. Sinagra E, Romano C, Cottone M. Psychopharmacological treatment and psychological interventions in irritable bowel syndrome. Gastroenterol Res Pract 2012;2012:486067.

2. Belcaro G, Gizzi G, Pellegrini L, Corsi M, Dugall M, Cacchio M, Feragalli B, Togni S, Riva A, Eggenhoffner R, Giacomelli L. Supplementation with a lecithin-based delivery form of Boswellia serrata extract (Casperome ${ }^{\circledast}$ ) controls symptoms of mild irritable bowel syndrome. Eur Rev Med Pharmacol Sci 2017;21(9):2249-54.

3. Chey WD, Kurlander J, Eswaran S. Irritable bowel syndrome: a clinical review. JAMA 2015;313(9):949-58.

4. Soares RL. Irritable bowel syndrome: A clinical review. World J Gastroenterol 2014;20(34):12144-60.

5. Noddin L, Callahan M, Lacy BE. Irritable bowel syndrome and functional dyspepsia: different diseases or a single disorder with different manifestations? MedGenMed 2005;7(3):17.

6. Scalera A, Loguercio C. Focus on irritable bowel syndrome. Eur Rev Med Pharmacol Sci 2012;16(9):1155-71.

7. Saha L. Irritable bowel syndrome: pathogenesis, diag- nosis, treatment, and evidence-based medicine.World J Gastroenterol 2014;20(22):6759-73.

8. Maxwell PR, Mendall MA, Kumar D. Irritable bowel syndrome. Lancet 1997;350(9092):1691-5.

9. Canavan C, West J, Card T. The epidemiology of irritable bowel syndrome. Clin Epidemiol 2014;6:71-80.

10. Grundmann O, Yoon SL. Irritable bowel syndrome: Epidemiology, diagnosis and treatment: An update for healthcare practitioners. J Gastroenterol Hepatology $2010 ; 25(4): 691-9$.

11. National Institute for Health and Care Excellence. Developing NICE guidelines: the manual [internet]. London: National Institute for Health and Care Excellence (NICE); 2015.

12. Lovell RM, Ford AC. Global prevalence of and risk factors for irritable bowel syndrome: a meta-analysis. Clin Gastroenterol Hepatol 2012;10(7):712-21.

13. Houghton LA, Atkinson W, Whitaker RP, Whorwell PJ, Rimmer MJ. Increased platelet depleted plasma 5-hydroxytryptamine concentration following meal ingestion in symptomatic female subjects with diarrhoea predominant irritable bowel syndrome. Gut 2003;52(5):663-70.

14. van der Veek PP, Dusseldorp E, van Rood YR, Masclee AA. Testing a biobehavioral model of irritable bowel syndrome.Eur J Gastroenterol Hepatol 2010;22(4):412-9.

15. Bellini M, Gambaccini D, Stasi C, Urbano MT, Marchi S, Usai-Satta P. Irritable bowel syndrome: A disease still searching for pathogenesis, diagnosis and therapy. World J Gastroenterol 2014;20(27):8807-20.

16. Mohammed I, Cherkas LF, Riley SA, Spector TD, Trudgill NJ. Genetic influences in irritable bowel syndrome: a twin study. Am J Gastroenterol 2005;100(6):1340-4.

17. Park MI, Camilleri M. Genetics and genotypes in irritable bowel syndrome: implications for diagnosis and treatment. Gastroenterol Clin North Am 2005;34(2):305-17.

18. Colucci R, Gambaccini D, Ghisu N, Rossi G, Costa F, Tuccori M, De Bortoli N, Fornai M, Antonioli L, Ricchiuti A, Mumolo MG, Marchi S, Blandizzi C, Bellini M. Influence ofthe serotonintransporter 5HTTLPR polymorphism on symptomseverity in irritable bowel syndrome. PLoS One 2013;8(2):e54831.

19. Chumpitazi BP, Shulman RJ. Underlying molecular and cellular mechanisms in childhood irritable bowel syndrome. Molecular and Cellular Pediatrics 2016;3:11.

20. Drossman DA. Functional gastrointestinal disorders: history, pathophysiology, clinical features and Rome IV. Gastroenterology 2016;150:1262-79.

21. Posserud I, Ersryd A, Simrén M. Functional findings in irritable bowel syndrome. World J Gastroenterol 2006;12(18):2830-8.

22. Lehrer JK. Irritable Bowel Syndrome. Medscape. Available at http:// emedicine.medscape.com/article/180389. 2017. Updated: Apr 04, 2017.

23. De Ponti F. Pharmacology of serotonin: what a clinician should know. Gut 2004;53(10):1520-35.

24. Mayer EA, Bradesi S. Alosetron and irritable bowel syndrome. Expert Opin Pharmacother 2003;4(11):2089-98.

25. Farzaei $M H$, Bahramsoltani R, Abdollahi M, Rahimi R. The Role of Visceral Hypersensitivity in Irritable Bowel Syndrome: Pharmacological Targets and Novel Treatments. Journal of Neurogastroenterology and Motility 2016;22(4):558-74.

26. Dorn SD, Palsson OS, Thiwan SI, Kanazawa M, Clark WC, van Tilburg MA, Drossman DA, Scarlett Y, Levy RL, Ringel Y, Crowell MD, Olden $\mathrm{KW}$, Whitehead WE. Increased colonic pain sensitivity in irritable bowel syndrome is the result of an increased tendency to report pain rather than increased neurosensory sensitivity. Gut 2007;56(9):12029.

27. Nozu T, Kudaira M, Kitamori S, Uehara A. Repetitive rectal painful distention induces rectal hypersensitivity in patients with irritable bowel syndrome. J Gastroenterol 2006;41(3):217-22.

28. Mertz H. Role of the brain and sensory pathways in gastrointestinal sensory disorders in humans. Gut 2002;51(1):i29-i33.

29. Bonaz B, Baciu M, Papillon E, Bost R, Gueddah N, Le Bas JF, Fournet J, Segebarth $C$. Central processing of rectal pain in patients with irritable bowel syndrome: an fMRI study. Am J Gastroenterol 2002;97(3):654-61.

30. Koloski NA, Jones M, Kalantar J, Weltman M, Zaguirre J, Talley NJ. The brain-gut pathway in functional gastrointestinal disorders is bidirectional: a 12-year prospective population-based study. Gut 2012;61(9):1284-90. 
31. Stasi C, Rosselli M, Bellini M, Laffi G, Milani S. Altered neuroendocrine-immune pathways in the irritable bowel syndrome: the top-down and the bottom-up model. J Gastroenterol 2012; 47(11):1177-85.

32. Dinan TG, Quigley EM, Ahmed SM, Scully P, O'Brien S, O'Mahony L, O'Mahony S, Shanahan F, Keeling PW. Hypothalamic-pituitary-gut axis dysregulation in irritable bowel syndrome: plasma cytokines as a potential biomarker? Gastroenterology 2006;130(2):304-11.

33. Hanevik K, Wensaas KA, Rortveit G, Eide GE, Mørch K, Langeland $\mathrm{N}$. Irritable bowel syndrome and chronic fatigue 6 years after giardia infection: a controlled prospective cohort study. Clin Infect Dis 2014;59(10):1394-400.

34. Du Pont AW. Postinfectious irritable bowel syndrome. Clin Infect Dis 2008;46(4):594-9.

35. Guinane CM, Cotter PD. Role of the gut microbiota in health and chronic gastrointestinal disease: understanding a hidden metabolic organ. Therap Adv Gastroenterol 2013;6(4):295-308.

36. Hyland NP, Quigley EM, Brint E. Microbiota-host interactions in irritable bowel syndrome: Epithelial barrier, immune regulation and brain-gut interactions.World Journal of Gastroenterology: WJG 2014;20(27):8859-66.

37. Ohman L, Simrén M. Intestinal microbiota and its role in irritable bowel syndrome (IBS). Curr Gastroenterol Rep 2013;15(5):323.

38. Atkinson W, Sheldon TA, Shaath N, Whorwell PJ. Food elimination based on IgG antibodies in irritable bowel syndrome: a randomised controlled trial. Gut 2004;53(10):1459-64.

39. Elli L, Branchi F, Tomba C, Villalta D, Norsa L, Ferretti F, Roncoroni L, Bardella MT. Diagnosis of gluten related disorders: Celiac disease, wheat allergy and non-celiac gluten sensitivity. World Journal of Gastroenterology: WJG 2015;21(23):7110-9.

40. Biesiekierski JR, Peters SL, Newnham ED, Rosella O, Muir JG, Gibson PR. No effects of gluten in patients with self-reported non-celiac gluten sensitivity after dietary reduction of fermentable, poorly absorbed short-chain carbohydrates. Gastroenterology 2013;145(2):320-8.

41. Seo AY, Kim N, Oh DH. Abdominal Bloating: Pathophysiology and Treatment.Journal of Neurogastroenterology and Motility 2013;19(4):433-53.

42. Layer P, Keller J, Loeffler $H$, Kreiss A. Tegaserod in the treatment of irritable bowel syndrome (IBS) with constipation as the prime symptom. Therapeutics and Clinical Risk Management 2007;3(1):107-18

43. Bonavita V, De Simone R. Towards a definition of comorbidity in the light of clinical complexity. Neurol Sci 2008;29(1):S99-102.

44. Gralnek IM, Hays RD, Kilbourne A, Naliboff B, Mayer EA. The impact of irritable bowel syndrome on health-related quality of life. Gastroenterology 2000;119(3):654-60.

45. Hungin AP, Molloy-Bland M, Claes R, Heidelbaugh J, Cayley WE Jr, Muris J, Seifert B, Rubin G, de Wit N. Systematic review: the perceptions, diagnosis and management of irritable bowel syndrome in primary care - a Rome Foundation working team report. Aliment Pharmacol Ther 2014;40(10):1133-45.

46. Soubieres A, Wilson P, Poullis A, Wilkins J, Rance M. Burden of irritable bowel syndrome in an increasingly cost-aware National Health Service. Frontline Gastroenterology 2015;6:246-51.

47. Sunderland R. Irritable bowel syndrome in adults: symptoms, treatment and management. Nurs Stand 2017;31(26):52-63.

48. Drossman DA, Thompson WG, Talley NJ, Funch-Jensen P, Janssens J, Whitehead WE. 4 Identification of subgroups of functional bowe disorders. Gastroenterology International 1990;3(4):159-72.

49. Thompson WG, Longstreth GF, Drossman DA, Heaton KW, Irvine EJ, Miller-Lissner SA. Functional bowel disorders and functional abdominal pain. Gut 1999;45(2):I143-7.

50. Drossman DA. The Functional Gastrointestinal Disorders and the Rome III Process. Gastroenterology 2006;130(5):1377-90.

51. Schmulson MJ, Drossman DA. What Is New in Rome IV. Neurogastroenterol Motil 2017;23(2):151-63.

52. Lacy BE, Mearin F, Chang L, Chey WD, Lembo AJ, Simren M, Spiller R. Bowel disorders. Gastroenterology 2016;150(6):1393-407.

53. Simren M, Palsson OS, Whitehead WE. Update on Rome IV Criteria for Colorectal Disorders: Implications for Clinical Practice. Curr Gastroenterol Rep 2017;19(4):15

54. Johannesson E, Simrén M, Strid H, Bajor A, Sadik R. Physical activity improves symptoms in irritable bowel syndrome: a randomized controlled trial. Am J Gastroenterol 2011;106(5):915-22.

55. lovino P, Bucci C, Tremolaterra F, Santonicola A, Chiarioni G. Bloating and functional gastro-intestinal disorders: Where are we and where are we going?World Journal of Gastroenterology: WJG 2014;20(39):14407-19.

56. Spiller R, Aziz Q, Creed F Emmanuel A, Houghton L, Hungin P, Jones R, Kumar D, Rubin G, Trudgill N, Whorwell P. Guidelines on the irritable bowel syndrome: mechanisms and practical management. Gut 2007;56(12):1770-98.

57. Volta U, Pinto-Sanchez MI, Boschetti E, Caio G, De Giorgio R, Verdu EF. Dietary Triggers in Irritable Bowel Syndrome: Is There a Role for Gluten? Journal of Neurogastroenterology and Motility 2016;22(4):547-57.

58. Catassi C, Bai JC, Bonaz B, Bouma G, Calabrò A, Carroccio A, Castillejo G, Ciacci C, Cristofori F, Dolinsek J, Francavilla R, Ell L, Green P, Holtmeier W, Koehler P, Koletzko S, Meinhold C, Sanders $D$, Schumann M, Schuppan D, Ullrich R, Vécsei A, Volta U, Zevallos V, Sapone A, Fasano A. Nonceliac gluten sensitivity: the new frontier of gluten related disorders. Nutrients 2013;5(10):3839-53.

59. Magge S, Lembo A. Low-FODMAP Diet for Treatment of Irritable Bowel Syndrome. Gastroenterol Hepatol (N Y) 2012;8(11):739-45.

60. Bijkerk CJ, Muris JW, Knottnerus JA, Hoes AW, de Wit NJ.Bijkerk CJ, Muris JW, Knottnerus JA, Hoes AW, de Wit NJ. Systematic review: the role of different types of fibre in the treatment of irritable bowel syndrome. Aliment Pharmacol Ther 2004;19(3):245-51.

61. Anastasi JK, Capili B, Chang M. Managing irritable bowel syndrome. Am J Nurs 2013;113(7):42-52.

62. Fukudo S, Hongo M, Kaneko H, Takano M, Ueno R. Lubiprostone increases spontaneous bowel movement frequency and quality of life in patients with chronic idiopathic constipation. Clin Gastroenterol Hepatol 2015;13(2):294-301.

63. Sarosiek I, Bashashati M, Alvarez A, Hall M, Shankar N, Gomez Y, McCallum RW, Sarosiek J. Lubiprostone Accelerates Intestinal Transit and Alleviates Small Intestinal Bacterial Overgrowth in Patients With Chronic Constipation. Am J Med Sci 2016;352(3):231-8.

64. Videlock EJ, Cheng V, Cremonini F. Effects of Linaclotide in Patients With Irritable Bowel Syndrome With Constipation or Chronic Constipation: A Meta-analysis. Clin Gastroenterol Hepatol 2013;11(9):1084-92.

65. Rao SS, Quigley EM, Shiff SJ, Lavins BJ, Kurtz CB, MacDougall $\mathrm{JE}$, Currie MG, Johnston JM. Effect of linaclotide on severe abdominal symptoms in patients with irritable bowel syndrome with constipation. Clin Gastroenterol Hepatol 2014;12(4):616-23.

66. Brandt LJ, Chey WD, Foxx-Orenstein AE, Schiller LR, Schoenfeld PS, Spiegel BM, Talley NJ, Quigley EM. An evidence-based position statement on the management of irritable bowel syndrome. Am J Gastroenterol 2009;104:S1-35.

67. Weinberg DS, Smalley W, Heidelbaugh JJ, Sultan S, Amercian Gastroenterological Association. American Gastroenterological Association Institute Guideline on the pharmacological management of Irritable bowel syndrome. Gastroenterology 2014;147(5):1146-8.

68. Chang L, Lembo A, Sultan S. American Gastroenterological Association Institute Technical Review on the pharmacological management of irritable bowel syndrome. Gastroenterology 2014;147(5):1149-72.

69. Gunn MC, Cavin AA, Mansfield JC. Management of irritable bowel syndrome. Postgrad Med J 2003;79:154-8.

70. Özdener $A E$, Rivkin A. Eluxadoline in the treatment of diarrhea-predominant irritable bowel syndrome. Drug Design, Development and Therapy 2017;11:2827-40.

71. Cash BD, Lacy BE, Schoenfeld PS, Dove LS, Covington PS. Safety of Eluxadoline in Patients with Irritable Bowel Syndrome with Diarrhea. The American Journal of Gastroenterology 2017;112(2):365-374.

72. Rivkin A, Rybalov S. Update on the Management of DiarrheaPredominant Irritable Bowel Syndrome: Focus on Rifaximin and Eluxadoline. Pharmacotherapy 2016;36(3):300-16.

73. Foxx-Orenstein AE. New and emerging therapies for the treatment of irritable bowel syndrome: an update for gastroenterologists. Therap Adv Gastroenterol 2016;9(3):354-75.

74. Hadley SK, Gaarder SM. Treatment of Irritable Bowel Syndrome. Am Fam Physician 2005;72(12):2501-8.

75. Ford AC, Talley NJ. Irritable bowel syndrome. BMJ 2012;345:e5836.

76. Wall GC, Bryant GA, Bottenberg MM, Maki ED, Miesner AR. Irritable bowel syndrome: a concise review of current treatment concepts. World J Gastroenterol 2014;20(27):8796-806.

77. Moayyedi P, Ford AC, Talley NJ, Cremonini F, Foxx-Orenstein AE, 
Brandt LJ, Quigley EM. The efficacy of probiotics in the treatment of irritable bowel syndrome: a systematic review. Gut 2010;59(3):32532.

78. Shanahan F, Quigley EM. Manipulation of the microbiota for treatment of IBS and IBD-challenges and controversies. Gastroenterology 2014;146(6):1554-63.

79. Ford AC, Quigley EM, Lacy BE, Lembo AJ, Saito YA, Schiller LR, Soffer $\mathrm{EE}$, Spiegel BM, Moayyedi P. Efficacy of prebiotics, probiotics, and synbiotics in irritable bowel syndrome and chronic idiopathic constipation: systematic review and meta-analysis. Am J Gastroenterol 2014;109(10):1547-61.

80. Pinn DM, Aroniadis OC, Brandt LJ. Is Fecal Microbiota Transplantation the Answer for Irritable Bowel Syndrome? A Single-Center Experience. Am J Gastroenterol 2014;109(11):1831-2.

81. Borody TJ, Warren EF, Leis SM, Surace R, Ashman O, Siarakas S. Bacteriotherapy using fecal flora: toying with human motions. J Clin Gastroenterol 2004;38(6):475-83.

82. Tian H, Ding C, Gong J, Ge X, McFarland LV, Gu L, Wei Y, Chen Q, Zhu W, Li J, Li N. Treatment of Slow Transit Constipation With Feca Microbiota Transplantation: A Pilot Study. J Clin Gastroentero 2016;50(10):865-70.

83. Zhao Y, Yu YB. Intestinal microbiota and chronic constipation. Springerplus 2016;5(1):1130.

84. Hadley SK, Gaarder SM. Treatment of Irritable bowel syndrome. Am Fam Physician 2005;72(12):2501-6.

85. Lucak S, Chang L, Halpert A, Harris LA. Current and emergent phar- macologic treatments for irritable bowel syndrome with diarrhea: evidence-based treatment in practice.Therap Adv Gastroenterol 2017;10(2):253-75.

86. Owyang C. Irritable bowel syndrome. In; T Yamada (eds). Textbook of Gastroenterology, 5th edn. Philadelphia: Lippincott Williams and Wilkins; 2009;pp.1536-74.

87. Fukudo S, Kinoshita Y, Okumura T, Ida M, Hayashi K, Akiho $\mathrm{H}$, Nakashima $\mathrm{Y}$, Haruma K. Effect of ramosetron in female patients with irritable bowel syndrome with diarrhea: a phase III long-term study. J Gastroenterol 2016;51(9):874-82.

88. Sinagra E, Morreale GC, Mohammadian G, Fusco G, Guarnotta V, Tomasello G, Cappello F, Rossi F, Amvrosiadis G, Raimondo D. New therapeutic perspectives in irritable bowel syndrome: Targeting lowgrade inflammation, immuno-neuroendocrine axis, motility, secretion and beyond. World J Gastroenterol 2017;23(36):6593-27.

89. Ford AC, Talley NJ, Schoenfeld PS, Quigley EM, Moayyedi P. Efficacy of antidepressants and psychological therapies in irritable bowel syndrome: systematic review and meta-analysis. Gut 2009;58(3):36778.

90. Gorard DA, Libby GW, Farthing MJ. Effect of a tricyclic antidepressant on small intestinal motility in health and diarrhea-predominant irritable bowel syndrome. Dig Dis Sci 1995;40(1):86-95.

91. Sinagra E, Romano C, Cottone M. Psychopharmacological Treatment and Psychological Interventions in Irritable Bowel Syndrome. Gastroenterology Research and Practice 2012;2012:486067. 